Izvorni znanstveni rad

DOI: $10.17234 /$ Croatica.41.3

UDK: 821.163.42-2.09:821.133.1-2Molière

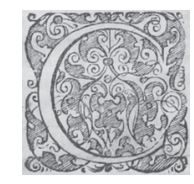

\title{
NEUKI NAUK, VIŠAK I MANJAK: O DUBROVAČKIM PRERADBAMA ŠKOLE ZA ŽENE I NJEZINE KRITIKE
}

\author{
Lada Čale Feldman \\ Filozofski fakultet Sveučilišta u Zagrebu \\ lcfeldma@ffzg.hr
}

Članak analizira dvije dubrovačke prilagodbe Molièreovih komedija Škole za žene i Kritike škole za žene u svjetlu feminističkih interesa. Upozoravajući na simptomatske propuste, otklone i proširenja izvornika, prilog ističe do koje su mjere prilagodbe uspjele upregnuti Molièreove tekstove u duhovitu reakciju na puno strože kodove ženskog i muškog ophođenja, a opet, s lingvističkog stajališta, puno prizemnije konverzacijske uzuse onodobnog dubrovačkog plemstva.

Ključne riječi: Molière, Škola za žene, Kritika Škole za žene, prilagodba, feministička kritika

Bila sam za moje grijehe otišla vidjet onu poganiju rutinavu od Nauka od žena koja mi je uzrokovala jedno pomanjkanje strahovito u srcu da me je strah koliko će proć vremena dokle se opeta povratim i rekuperam.

(Pera u Suproć onijem koji su zabavili Nauk od žena)

Moja će znanstvena "crtica" nastojati dati obol četirima ključnim interesima profesorice Dunje Fališevac: prvo, dakako, njezinoj ljubavi prema starijoj hrvatskoj književnosti kao korpusu u kojemu je uvijek znala naći poneku dotad neotkrivenu uzbudljivost; drugo, njezinoj komparatističkoj otvore- 
nosti, korijenski protivnoj zagovoru nacionalno-književne autarkije; treće, njezinoj sklonosti zabavnom, smiješnom i komičnom kao aspektima, strukturnim elementima i učincima koji sami po sebi već sugeriraju prkos prema svakoj ortodoksiji; četvrto, njezinu "mekom" feminizmu - ne samo brizi za zapostavljene junakinje povijesti naše književnosti i kulture, bilo da su u pitanju autorice ili likovi, nego i načelnim kritičkim sugestijama na račun nasljeđa patrijarhata, sugestijama koje su međutim svaku možebitnu primisao kako je riječ o puku pristranom zadijevanju uvijek znale otkloniti trijeznom prosudbom i pouzdanom potkrepom. Mogu se samo nadati da će i moja nastojanja ovom prigodom biti na toj visini: namjera mi je i opet našu slavljenicu obdariti jednim, sad međutim izričito "ženskim” čitanjem frančezarija, a ponovno na tragu njezina priloga diskusiji o tome "Na koji su jezik Dubrovčani prevodili Molièrea?" (Fališevac 2007).

Upravo će me naime zanimati problem jezika, njegovih izvornih i prijevodnih viškova i manjkova, a osobito njegova prevrtljiva sposobnost da rečenim nadomješta i nagovješćuje i ono što ostaje neizrečeno, to više što je baš ta prevrtljivost, kako ću pokazati, ujedno i prava protagonistica predloška kojim ću se baviti, Molièreove Škole za žene, pa i onakve kakva je, pod naslovom Nauk od žena, našla puta do dubrovačkog uha. Imamo li pak na umu činjenicu da je posrijedi komad koji je Molièreu priuštio brojne polemičke reakcije i samog ga nagnao da dopiše i svoju Kritiku Škole za žene alias, na dubrovačkom, Suproć onijem koji su zabavili Nauk od žena - novi komad dakle u kojemu se naširoko raspravlja baš o jeziku prethodne, kobne komedije - povodi će se za tumačenje samo uvišestručiti. Dubrovačka će naime inačica dramatizirane polemike, logično, morati u sebe ugraditi svijest o dvama izvornicima - ك̌koli za žene i Kritici Škole za žene - i jednoj preradbi, Nauku od žena, te polemiku zapravo ujedno voditi i o potonjoj, "istomačenoj", a ne samo o francuskoj, autorskoj verziji.

Slučaj dviju, odnosno četiriju komedija postaje to zanimljiviji znamo li da se još od početnih usporedbi francuskih predložaka i dubrovačkih prilagodbenih inačica o potonjima sudilo kao znatno neukijima: tako i Fališevac kaže da je u njima stih pretakanjem u prozu izgubio štošta od svoje "profinjenosti", uvelike i stoga što su preradbe, i kad bi se izvornika razmjerno čvrsto pridržavale, $u$ replike likova ubacivale ne samo talijanizme nego i "zamjenski tekst pun amplifikacija, s brojnim primjerima iz banalnoga suvremenog dubrovačkog života", koji su uvelike kvarili "konciznost" originala. Nabrojeni su viškovi međutim ako ne uzrokovali, onda pratili i neke manjkove, i to ne samo "komičnog i smiješnog", osobito "komičnih motiva 
i scena na račun precioznosti i galantnosti”, nego i manjkove potvrda o "metatekstualnosti i književnoestetskoj polemičnosti" (ibid.: 266-267). No Nauk od žena, premda mu i radnja, slijedom namjera izvornika, kako bi se Barbara Johnson izrazila, "poučava neznanju", odnosno naukuje neukost, ${ }^{1}$ možda sâm ipak i nije tako neuk, što ne znači da u njemu nije moguće naći i viškova i manjkova u odnosu na izvornik. Ključno je međutim tu ustvrditi koliko oni dubrovačkoj verziji daju ili oduzimaju na komičnosti, pogotovo kada se toj matematici pridruže okolnosti uz koje se spomenuti jezični manjkovi i viškovi primarno vezuju. Oni se naime i u izvorniku i u preradbi najčešce tiču seksualnosti, nauka do kojega žene, osobito mlade, i one za udaju, nipošto ne smiju nenadzirano prispjeti, i koji je pravo izvorište skandaliziranih reakcija što ih komično uprizoruje Kritika Škole za žene, odnosno dubrovačka Suproć onijem koji su zabavili Nauk od žena. Činjenica pak da je riječ "zabava" u ono vrijeme, kako tvrdi Deanović, značila upravo "mana, nedostatak" (usp. Deanović 1973: 382) - iz čega bi onda ishodilo da riječ "zabaviti” u naslovu druge preradbe valja razumjeti kao "pronalaziti manjkove, nedostatke i greške" - može nas danas samo dodatno - zabaviti.

Što je dakle tako strašnoga publika čula i vidjela u Školi za žene, što u Nauku od žena? Ako je suditi po francuskoj Kritici Škole za žene, preciozna se publika Molièreova doba i podneblja ćudoredno zgražala nad trima Agnezinim replikama i jednom sluge Alaina, od kojih za prve dvije, jednu stvarnu i jednu tek zamišljenu, saznajemo od Agnezina tutora i nesuđenog ženika Arnolphea: prvo, nad njezinim bezazlenim pitanjem rađaju li se djeca kroz uši; drugo, nad njezinim mogućim odgovorom u društvenoj igri rimovanja, koji bi, uvjeren je Arnolphe, prije glasio "tarte à la crème", tj. torta sa šlagom, i jednako potvrdio njezinu bezazlenost nego što bi se ikad u Agnezinim ustima zamijenio kakvom opscenošću koju pitanje "qu'y met on (i što se tamo stavi)?” izaziva, a koja bi se bolje rimovala; ${ }^{2}$ treće, nad Alainovom usporedbom žene s "juhom" u koju je samo mužu dopušteno umakati prste; naposljetku četvrto, nad Agnezinim isprekidanim odgovorom

1 Tekst Barbare Johnson doslovce se zove "Poučiti neznanju" ("Teaching ignorance"), a bavi se ne samo načinom na koji Arnolphe pokušava Agnezu poučiti kako da ostane potpunom neznalicom nego i metaforičkom protegom te ideje na dekonstrukcijski nauk, točnije, pretpostavkom da uvijek, poput i nehotično prkosne Agneze, učimo mimo htijenja svojih naučavatelja, kao i usprkos onomu čemu nas se eksplicitno teži poučiti (usp. Johnson 1982).

2 Posrijedi je antologijska rečenica, koja se uobičajila navoditi i izvan matičnoga konteksta, kao da ga s jedne strane automatski priziva, a s druge strane kao da asocira baš potpunu odcijepljenost smisla od prikladno pridružene semantičke zapremine označenog navedenoga označitelja. 
na Arnolpheovo pitanje o tome je li joj mladi Horace, kad je s njome razgovarao, još štogod i uzeo, tijekom koje isprekidanosti Arnolpheu pozlije jer nikako da dočeka što je na stvari. U francuskome je izvorniku posrijedi neprevodivo ponavljanje člana le kojemu će se naposljetku dometnuti riječ cordon, što znači "ukrasna vrpca", usuprot svim besramnicima koji su u praznine dijaloga dotad silom htjeli učitati kakav sramni djelić ženske anatomije.

A dubrovački prijevod, odnosno prilagodba? Prva je replika - "rađaju li se djeca kroz uši” - prevedena doslovno, to jest doslovno samo ako uši zapušimo za činjenicu da sama izvorna replika, osim religijskih konotacija, ${ }^{3}$ dvosmisleno doziva provodnu tematsku nit komada, sugestiju naime da su riječi, dakle ono što prolazi kroz uši, najopasnije oruđe seksualne (samo)spoznaje, a onda i kanal koji vodi do mogućih potomaka. Arnolphe je toga itekako svjestan, pa nauk seksualne neukosti striktno prate njegove invektive protiv ženske učenosti i izričite zabrane Agnezi da čita i piše, paradoksalno međutim i opet ukoričene u knjizi maksima iz koje joj naređuje da čita i izuči kakva buduća supruga ima biti. Spomenute invektive, kada je posrijedi dubrovačka preinaka, same su za sebe zanimljiv adaptacijski simptom: Pavličićeva analiza razloga zbog kojih su i one zadobile specifično versifikacijsko i stilsko ruho - sestine s rimom ababcc, svojstvene Gundulićevim i Đurđevićevim baroknim poemama - argumentirano je pokazala da je dubrovački prerađivač i tim, metametričkim aluzijama u pamet htio dozvati vlastitu tradiciju rasprava o granicama ženske doličnosti, točnije pobožne stihove posvećene raspusnim Mandalijenama (Pavličić 1985: 78-79). No i tu teško da je bila riječ o pukome signalu voljna priključka na versifikacijske uzuse na koje je publika navikla: dubrovački je adaptator očito time ujedno dozivao i smutljivu moć jezika, ambivalentnu spregu užitka u opisu erotskih draži i moralističkoga tona kojim se žensko kićenje i ini prekršaji pravila lijepog ponašanja u dubrovačkih prethodnika osuđuju.

Naputci kojima se Agneza sili na "nauk" tek su dodatna potkrepa pretpostavci da je u Dubrovniku 18. stoljeća vladao i gori zapt, jer i sam Pavličić sudi da je srodnih pouka koje su kružile u rukopisu tada zasigurno bilo, no da je pretežito riječ bila o izdancima pučke književnosti koja je umetkom u preradbu zadobila pravo da zaigra "ulogu dobre, tradicijom

3 Posrijedi je plod Agnezina samostanskog naukovanja u okviru kojega joj se ucjepljivalo teološko tumačenje Isusova začeća koje pokušava prikladno odgovoriti na pitanje o Marijinoj bezgrešnoj oplodnji (usp. Zukaitis 2009). 
posvećene literature" (ibid.: 79). ${ }^{4}$ Lambro se možda i zbog tog kolebljivog vrijednosnog statusa "dobre, tradicijom posvećene", a opet i nabožne i poučne literature, osobito u odnosu na pomodarske književne trendove, posebice obara upravo na prijevodne ambicije dubrovačkih vlasteličića jer će već s početka komedije grmjeti ne samo da neće da mu žena zna "ni što je proza a nekmoli veras" nego i, sasvim konkretno, protiv "frančezarija i talijanarija i versarija" (Deanović 1972: 145), što je zasigurno dodatno nasmijavalo dubrovačku publiku, s nemalim metatekstnim i književnoestetski polemičnim učincima. No spomenuti komični višak kojim se Lambro, i sam plod frančezarijskih "krađa", obara na uvezene novotarije koje kvare mlade žene, odmah se u preradbi kompenzira i značajnim manjkom jer netom nakon te filipike, kada bi u izvorniku nastupila slavna tarte à la crème, dubrovački prevoditelj šuti, vjerojatno zato što srodne društvene igre rimovanja u kojoj bi se žene na tako bezočan način izazivale dubrovački salon nije poznavao, a možda i zato da izbjegne bar ovu primisao neizrečene, a ipak baš tom odsutnošću dozvane opscenosti.

Ovo samo po sebi ne bi bilo toliko značajno, da nema dubrovačke inačice Kritike Škole za žene u kojoj se, kako rekosmo, opsežno raspravlja o jezičnoj politici prethodnoga komada, odnosno njegove dubrovačke preradbe. Suproć onijem koji su zabavili Nauk od žena naime kao prekršaj ćudoređa ne navodi samo već spomenuto pitanje o tome kako djeca dolaze na svijet, nego i niz riječi od kojih Peri, dubrovačkoj varijanti precioze Climène, ide na povraćanje: smijeh je to veći što se te riječi i tiču jela francuska "juha" postala je "menestra", ali zašto je Peri cijela komedija zasmrdjela pri spomenu "gruja", dubrovačkoga naziva za ribu ugor, to svakom čitatelju postojeće verzije Nauka od žena mora ostati nejasno, jer te riječi u dubrovačkom tekstu naprosto nema. Mogli bismo nagađati nije li neka nepronađena i necenzurirana verzija možda ipak smogla snage da se nosi s nesretnom Molièreovom “tortom", jer po svemu ishodi da "gruj” zamjenjuje upravo nju - skrećući pritom opscene aluzije teksta u pravcu muške fiziologije - ali to zasad ne možemo kategorički tvrditi. Možda je baš zato što je riječ u Nauku od žena nepronalaziva i smiješan njezin opetovani doziv u dubrovačkoj Kritici Škole za žene, kad u salon koji o kazalištu raspravlja

4 Pavličić u prilog toj pretpostavci spominje dva spjeva, Od privare i zle naravi ženske Ivana Ivaniševića te Marka Arnerića Opravdanje dobrih žena, spjev koji s prethodnim polemizira, no ključno je da su ispisani istom formom te da "oba govore o ženskoj prirodi i ponašanju, jedan napadajući žene, a drugi braneći ih i opravdavajući” (Pavličić 1985: 79). 
uđe Mato, i on se zgražajući nad istom riječju, uza svu činjenicu što će joj u vlastitoj rečenici kao susjedu posve nesvjesno i olako pridružiti u Dubrovniku udomaćenu talijansku vulgarnu poštapalicu cazzo, istih značenjskih asocijacija. Zasigurno je Mato time i opet proizveo višak veselja među publikom u Orsanu, izazvavši u dijalogu samoga komada autentično nominalističkorealističko natezanje i to, izgleda, oko samog fundamentalnog označitelja falogocentrizma:

Mato: Ah, per verità, imaš razlog, "gruj”! To je ono što sam bio zasenjo i jes od maloprije da mi se vrti po pameti! Zahvaljivam vam, gospo, da ste mi se činili opomenut o "gruju”; "gruj”, cazzo, "gruj”!

Frano: E ben, što hoćete rijet s tezijem "grujom"?

Mato: Cošpetto de Becco, "gruj”!

Frano: I veće nije drugo?

Mato: "Gruj”!

Frano: Ma reci nam što je to.

Mato: "Gruj!

Frano: Ma je od potrebe da nam odkriješ što je, što ti je u pameti s tezijem?

Mato: “Gruj”, gospo, a!

Frano: Ma koje zlo nahodiš u temu?

Mato: Ja ništa afatto. “Gruj”! (ibid.: 200).

Preostaje nam međutim još utvrditi što se zbilo s četvrtim jezičnim prekršajem iz Nauka od žena koji je i u drugim jezicima razmjerno teško prevesti. Agneza, podsjetimo, zapinje ponavljajući član "le" dok odgovara što joj je Horace možda uzeo. Dubrovačka će se inačica odlučiti međutim da nedostatak člana kompenzira zazornom dvosmislenošću samoga glagola:

Lambro: Da te nije Ane htio još gdje drugovdje, da ti nije digo.... (Videći da Anica ončas ne odgovara) $\mathrm{U}, \mathrm{u}, \mathrm{u}$ !

Anica: E, e, jes mi...

Lambro: Kako?

Anica: Digo....

Lambro: $\mathrm{U}, \mathrm{u}, \mathrm{u}$ !

Anica: On...

Lambro: Što si rekla?

Anica: Ne smijem rijet, er će tebi možebit žo bit na mene. 
Lambro: Neće.

Anica: Zaisto?

Lambro: Neće zaisto.

Anica: Da zakuni mi se.

Lambro: Neće na vjeru.

Anica: Digo mi je... Zaisto ćeš se ti rasrčit i jako me ćeš vikat.

Lambro: Neću.

Anica: Hoćeš.

Lambro: Neću, neću, neću, s malanom, dospjejmo je jedanput, što ti je digo?

Anica: Dig...

Lambro (zbande): Podnosim muke od pakla.

Anica: Digo mi je oni kordun što mi si bio darovo. Zaisto nijesam mogla od manje nego mu ga dat (ibid.: 156).

Suproć onijem koji su zabavili Nauk od žena neće ništa manje komično profitirati od netom dočaranoga otezanja i ponavljanja koje - za razliku od opetovana zvuka ipak prilično neutralnoga člana "le" u izvorniku - u ustima uglednih Dubrovkinja izaziva, psihoanalitičkim rječnikom rečeno, očit višak užitka:

Pera: Zovi ti kordun koliko je tebi drago: ma ono "digo mi je", dje ona pristaje i ne slijedi naprijeda što je počela, nije miga ono stavljeno za ne znam što. Više onega "digo..." prihodi priko pameti čudnovatijeh misli. Ono "digo..." dava jako zo izgled ko god ga čuje, i možeš govorit što god hoćeš, nećeš umijet nigda obranit neskladnos onoga "digo..."

Marija: Istina je, kužina, i ja sam ovdi od gospođine suproć onemu "digo..." Ono "digo..." neskladno je da se ne ima kud neskladnije, i zaisto ne imaš nikakva razloga branit ono "digo...." (ibid.: 192).

Daleko od toga da se jezična, a slijedom toga neizbježno i dramaturška usporedba dviju, odnosno četiriju komedija, dade zaustaviti samo na ovim, izvornim i prijevodnim igrama riječi oko ženskih i muških anatomskih i verbalnih viškova i manjkova. Da ta lingvističko-seksualna ekonomija ima primjerice i svoju pravno-novčanu stranu, koja se također morala lokalizirati, ponajbolje svjedoči zapletena "amplifikacija" što ju je u preradbi moralo doživjeti "kančilijerovo" razjašnjenje o uvjetima, propisima i posljedicama bračnoga sporazuma, ukoliko ga Arnolphe i Agneza, odnosno Lambro i Anica sklope. U izvorniku, situacija je komična zbog toga što Arnolphe, nesvjestan bilježnikove nazočnosti, ispovijeda svoju neizmjernu ljubav 
prema budućoj družici, toliko da mu bilježnik nudi niz mogućnosti da ju materijalno osigura, ne uviđajući kako Arnolphe nema namjeru da sasluša koja bi prava u različitim ugovornim kombinacijama buduća mladenka uistinu stekla. Bilježnikova ponuda od čak četiri različite inačice darovanja ovisno o tome tko kome što u brak donosi te tko kojim nasljeđem raspolaže u slučaju smrti bilo kojega od supružnika - u francuskome se izvorniku iznosi u svega sedam aleksandrinaca te baš zbog te zbijenosti kombinacijskih vratolomija izaziva zbunjenost i u sugovorniku Arnolphu, a tako i u kazališnom gledatelju, premda je pravno posve logična i jasna.

Dubrovačko proširenje nije tek pretočeno u prozu, nego i komičnost izaziva posve suprotnim učinkom raspredanja, odugovlačenja i usložnjavanja mogućih ugovornih okolnosti i ishoda. U odnosu na izvornik i nema toliko pravnih razlika, osim što je redoslijed pravnih inačica obrnut. Kančilijerova sklonost da se služi talijanskim i latinskim pravnim formulacijama, kako bi si dao važnost poput uzorna pedanta, doprinosi međutim daleko više od neosporno duhovite lapidarnosti Molièreova izvornog lika općem dojmu o braku kao o složenoj i detaljno reguliranoj seksualno-ekonomskoj transakciji. Iz njegova je monologa vidljivije koliko je žena onoga vremena, napose dubrovačka, bila prepuštena na milost i nemilost odlukama svojte i eventualnoj velikodušnosti muža u pogledu toga kakva će biti sudbina njezina imutka umre li prije nego što rodi djecu, ili pak nakon muža, kada se ili morala zadovoljiti tek četvrtinom svojega miraza, ili se, u najboljem slučaju, uza sve uživanje nekretnina i eventualno prije dogovorene rente, morala odricati sve pokretne imovine uz izuzetak nakita i kućne opreme.

Iz feminističke bi nam se perspektive nadalje moglo pokazati značajnim kako dubrovački tumači prevode i lokalno "prilagođuju" već ovdje spomenuti pojam "precioze": ${ }^{5}$ primjerice, kada se Arnolphe u izvorniku Škole za žene zgraža nad iznenadnom Agnezinom rječitošću i obranom ljubavne neovisnosti, pitajući se kako je moguće da tako britko odgovara, poput prave precioze (Voyez comme raisonne et répond la vilaine./ Peste, une précieuse en dirait-elle plus?), dubrovački Lambro neće za Aničinu drsku elokvenciju

\footnotetext{
Osobito znademo li da se među čak 23 prevedene Molièreove komedije - što je broj koji prevoditelji na književni hrvatski još nisu uspjeli doseći - nisu našle baš Smiješne precioze! U Dubrovniku naime nije postojao usporediv socijalni fenomen razmjerno autonomne ženske kulturne niše na koji bi se komedija mogla pozivati, osobito ne na relaciji provincija - grad na kojoj je francuski komediograf osovio svoju persiflažu.
} 
i autonomnu ljubavnu logiku naći tako laskav uzor kada kaže: "Pogledaj ko razloga u nje i kako odgovara bezočnica! Bi li tako odgovarala ona najgora s Pelina?"

Deanović nas revno informira da je posrijedi "najsjeverniji dio grada Dubrovnika, uz gradske zidine, gdje su stanovali siromašni građani", kao i da je na istome mjestu "u originalu: une précieuse" (Deanović 1972: 178), ali ništa ne kaže o tome što ta riječ znači, kao ni o nesrazmjerju izazvanom i više nego doslovnom lokalizacijom: Peline je naime četvrt iz koje su se zbog siromaštva regrutirale prostitutke, dok su precioze bile plemkinje kojima je pravo na ljubavnu samovolju, to jest na prekršaj ili odustanak od bračnih dužnosti, barem nominalno, jamčila upravo seksualna čistoća, uskrata odabranog ljubavnika, lojalnost viteškog kodeksa časti, ideal dvorske ljubavne distance (usp. Baumal 1926). Nemamo dakle ovdje samo posla s "banalnom dubrovačkom svakodnevicom", nego i sa suprotnim standardima ženske jezične slobode: što je u Dubrovniku žena više socijalno kotirala to je imala manje prava govoriti, jer se svaka jezična raspusnost automatski asocirala s bludničkom iskvarenošću.

Takav tretman riječi "precioza" vrijedi razmotriti u svjetlu adaptacije Kritike Škole za žene, kojoj se radnja izvorno odvija u salonu, mjestu kojim vladaju i u kojem se često spominju upravo precioze. U Suproć onijem koji su zabavili Nauk od žena međutim riječ "precioza" adaptator će prevesti tek kao karakterno obilježje smiješne samodopadnosti ("Je li ko drugi komu se može rijet onako istinito kako njoj ono što zovu bit smiješna, a puna same sebe..."), možda i zato jer se diskusija u kojoj se riječ spominje odvija na račun drugih pripadnica iste klase. Odabrana će se žrtva ogovaranja u nastavku dijaloga nazvati "jedna istornica veća od ovega svijeta", prepoznatljiva i po svojem smiješnom tjelesnom držanju i mehaničkim kretnjama, a dubrovačka prerada neće biti milosrdna ni prema znatno suzdržanijim bogomoljkama: prerađivač dorađuje i francusku repliku o čistunici markizi Araminti, jer i kad je Pero, pod imenom "gospođe Veće", krsti "vrijednom i pametnom vladikom", znakovito domeće kanda nehotični ustupak "zasve da je žena" (Deanović 1972: 195) kojeg u izvorniku nema.

No za dubrovačke će adaptatore ishitreno ponašanje ipak biti jednako inspirativno poprište duhovitih proširenja i kada metom smijeha i ruga postanu, vidi vraga, muški pripadnici dubrovačkog plemstva. Tako se jedna od izvorno salonskih dama, a na dubrovačkom ponajprije međusobnih srodnica, "bratučeda”, Marija, zgraža nad Aničinim "kužinićem” baš kao i Élise nad 
Uranijinim “markizom", ali dok se potonji u izvorniku tek smješta u društvo neumjesnih i neduhovitih dvorjana, Marija će se o Matu puno opširnije i konkretnije raspričati:

Ma kakvi god da su ostali, zaisto ne može se dišapitije stvari nego kad on dođe ter
počne atakavat s kojomgodi njegovom ranketivom, i u isto doba vidi mu se dje
cijeni da govori što galanto i spiritozo, a zaklela bih se da i on isti ne uzzna što
govori, zašto to uzbude samo mlatit što mu na pamet dođe bez kreance i rigvarda
od ikoga ko ga sluša. Onomadne ga nješto gledam z džilozije dje ide uz placu i
niz placu i ne propuštiva jedne butige i s jedne i s druge bande atakavajući s vrata
svakoga od butigara; nijesam mogla razumjet što govori, zasve da je viko u sve
glase, samo bih gledala dje bi oni siromah butigar na koga bi došo sto s klobukom
ali s baretom u ruci i, što bi mu se moglo poznat po faci, paralo bi da sam sobom
govori: 'Vlasteline, ostavi me stat'; pak bi se od svakoga odijelio smijući se k'o
mahnitac... (ibid.: 188).

Raspravi o prijevodno-prilagodbenim akcentima rodne problematike u Molièreovim izvornicima mogli bismo stoga, u duhu kraja netom navedenoga citata, dometnuti štogod i o intrigantnom "tomačiteljevu" sad kraćenju sad proširenju, to jest znatnom preinačenju rasprave o ukusu nižih i viših slojeva kazališne publike u Suproć onima koji su zabavili Nauk od žena. Dok u izvorniku primjerice Dorante hvali ukus partera koji se umije smijati onome nad čim se plemići i precioze zgražaju, dubrovačka će prilagodba utišati značaj pučana i Franovu polemiku razviti oko podjele unutar vlastelinskih redova, jer će njegov protivnik Mato čak i izrijekom imenovati istaknute pojedince na čiji bi se probrani ukus valjalo ugledati, vičući "nađi mi jednoga Antuna Franova, jednoga Dživa Marova, jednoga Vlaha Perova i ovakijeh koji se nije gadio i mrdio" (Deanović 1972: 195). Frano se neće, odgovarajući na napad, poput Dorantea osvrnuti na opća načela kazališnog ukusa, u kojemu prema francuskome liku može udjela uzeti svatko, bez obzira na statusnu pripadnost i obrazovanje, nego će se oboriti na one koje u sudu vodi socijalni konformizam, očito dominantan oblik pritiska u skučenim razmjerima dubrovačke onodobne elite:

Frano: Da, da, signor Matteo, i ti mi si od onezijeh koji držu da ništa ne valja što ne budu pohvalili ta čeljad kojijeh zoveš da su prid svakijem u končetu i stimani kako niko; a vas ti njihov končet ne uzdrži se u drugomu nego u njekijem kojunima koji imadu za čas služit ih i čekaju što će oni rijet za moć paka ko kroz čarabotanu govorit ali je što dobro ali rđavo. Ma ne boj se, imaš dosta te družine kojoj bi bilo jako mučno kad bi im se dogodilo na što nasmijat ali se arajdat, mogla bi bit najljepša stvar, kad bi poslije obaznali da se na to nije nasmijo niko od onezijeh za kojijem oni priguzivaju [...] 
[...] Najviše paka izidem izvan sebe kad vidim njekijeh koji za adulat onijem kojijem se po vazdan klanjaju ne znajući što govoru ni oni, osijecaju ko pleština i razlijegaju se više stvari kojijeh i ne razumijedu uzdajući se u ono što su od druzijeh čuli bez stavljat se da, ako druzi onako govore i neimadu razloga za onako govorit, znadu ako ništa da ono nije onako, nego imadu koju njihovu treću svrhu za koju onako govore [...] (ibid.: 195-196)

Svemu bi rečenom vrijedilo dometnuti i kratki komentar na sud o tome da su dubrovačke adaptacije unizile izvornike i zato što su redom u prozi; Kritika Škole za žene i tu bi cijelome lokalizacijskome pothvatu mogla priskočiti u pomoć kao prikladan argument u prilog tezi da ta odluka nije bila stvar puke nedoraslosti versifikacijskim zahtjevima izvornika. Kao što naime ističe Larry Norman (1999), spomenuta je komedija ključ Molièreove poetike "javnog zrcala" i po tome što se u njoj komediografsko umijeće po prvi put izjednačuje s umijećem neusiljene salonske konverzacije te eksplicite usađuje u samu publiku: salonska dama Uranie koja ravna poprištem u kojemu se odvija radnja Kritike, zabavljena duhom raspre, predložit će na kraju komada da se cjelokupna prepirka izravno, bez prevelikih dotjerivanja, prenese na pozornicu, da se, dapače, obrada prepusti u ruke Molièreu, koji bi umio održati svježinu razgovorne neposrednosti, dodatno poantiranu naglim upadom poziva na večeru kojim započinje završni, kratki prizor poziva, koji se spremno dočeka kao najprirodniji kraj koji bi se mogao zamisliti. Bez obzira na činjenicu da je, dakako, posrijedi "mit o neposrednoj prikazbi" (ibid.: 48) - uvjetovan specifičnim spletom povijesnih okolnosti unutar kojih se sama socijalna razmjena formulirala u terminima umjetnosti, omogućujući kružno zrcaljenje društvene i kazališne interakcije - valja istaknuti da su prozni izričaj i improvizirani karakter kraja koji će se svidjeti upravo ženskoj publici bili presudni čimbenici na kakvima se taj mit uopće mogao osoviti. Kao što je iscrpno pokazao Pavličić (usp. Pavličić 1985), "vlasteličići” su bili itekako vješti u manipulaciji različitim versifikacijskim obrascima vlastite tradicije, ali su ih redom držali indicijima prošlih, zastarjelih, "očinskih" literarnih vremena, kako ovdje svjedoči rug spram izvornoga Lysidasa, dubrovačkog Pera, koji kuka zbog toga što "nije veće jednoga Osmana, jedne Trublje slovinske, jednoga Sina razmetnoga, jedne Vide" (Deanović 1972: 201). Prepoznavši u završnim odlomcima Kritike upravo autorizaciju vlastita, amaterskog autorstva, u Suproć onijem koji su zabavili Nauk od žena vlasteličići neće trebati ničiju diskretnu pomoć oko transkripcije duhovite diskusije, nego će posve opravdano upisati sljedeće rečenice: 
Anica: Pokli je svak kontenat, gosparu Frano, nastojte se opomenut od svega, i pokli je veće umro Molijer, podajte sve ispisano ovoj Družini od zamršenijeh, koji su rečitali Nauk od žena, neka od svega ovega učine jednu komediju, a vi ih znate, ide im ovako od ruke (ibid.: 207).

Spomenuti su uvidi u duhovite otklone, redukcije i amplifikacije dubrovačkih prijevoda nadam se dovoljno posvjedočili da Molière, bar kada su u pitanju Škola za žene i njezina Kritika, u rukama dubrovačkih vlasteličića doduše jest pretrpio ubačaj mnogih vulgarizama, ali pritom nije izgubio na "profinjenosti": družine su, reklo bi se, potencirale svijest da se takvoj, u osnovi za njega precioznoj, ako ne i cenzorskoj uporabi jezika francuski komediograf kroz čitav svoj opus, a osobito u Kritici Škole za žene, neobuzdano podsmjehivao. Stoga se, da zaključim, dubrovačkog jezičnog ruha njegova opusa, ruha koji je u pitanjima višeznačja nastojao biti domišljat koliko i izvornik, nimalo ne treba stidjeti - dapače, vrijedi mu se iznova vraćati, pa i za volju feminističkoga nauka.

\section{LITERATURA}

Baumal, Francis. 1926. Féminisme au temps de Molière, La Renaissance du livre, Paris. Deanović, Mirko, prir. 1972/73. Dubrovačke preradbe Molièreovih komedija, Stari pisci hrvatski, knj. 36 i 37, JAZU, Zagreb.

Fališevac, Dunja. 2007. Dubrovnik, otvoreni i zatvoreni grad, Ljevak, Zagreb.

Johnson, Barbara. 1982. Teaching ignorance: L'École des Femmes, Yale French Studies 63, 165-182.

Dekker Lalande, Roxanne. 1996. Intruders in the Play World, The Dynamics of Gender in Molière's Comedies, Associated University Press, London.

Norman, Larry K. 1999. The Public Mirror, Molière and the Social Commerce of Depiction, The University of Chicago Press, Chicago and London.

Pavličić, Pavao. 1985. Stih u drami i drama u stihu, Zavod za znanost o književnosti i Sveučilišna naklada Liber, Zagreb.

Zukaitis, Kathryn. 2009. Religious Metaphor in Molière's L'École des Femmes, Glossolalia, (Journal of Yale Divinity School), sv. 1. 


\section{SUMMARY \\ IGNORANT SCHOOLING, MORE AND LESS: \\ DUBROVNIK ADAPTATIONS OF MOLIËRE'S SCHOOL FOR WIVES \\ AND THE CRITIQUE OF THE SCHOOL FOR WIVES}

The paper opts for the feminist perspective while analyzing two $18^{\text {th }}$ century Dubrovnik adaptations of Molière's School for Wives and the Critique of the School for Wives. By pointing out symptomatic omissions, alterations and expansions of the two original texts, the paper attempts to validate the extent to which these adaptations make Molière's texts humorously responsive to much stricter codes of gender conduct, and yet, from the linguistic point of view, to much less "refined" conversational discourse used by the Dubrovnik aristocracy of the time.

Keywords: Molière, School for Wives, Critique of the School for Wives, adaptation, feminist criticism 